\title{
The Pillars of Learning, Understanding, Studying and Explaining
}

\author{
Piero Mella \\ Department of Economics and Management, University of Pavia, Pavia, Italy \\ Email: piero.mella@unipv.it
}

Received 20 August 2014; revised 8 September 2014; accepted 20 September 2014

Copyright (C) 2014 by author and Scientific Research Publishing Inc.

This work is licensed under the Creative Commons Attribution International License (CC BY). http://creativecommons.org/licenses/by/4.0/

\section{Abstract}

This paper is based on the hypothesis that intelligent persons have a high capacity to understand and learn effectively, because processes involving study and explanation allow them to develop the capacity to construct a system of coherent models that can be quickly updated. The first part of the paper will highlight the logic and power of systemic understanding and learning that is founded in Systems Thinking. It is clear that understanding and learning represent different mental activities: We understand when we form a coherent model of a concept, but we learn only when that model becomes stable and permanent; when it is memorized so that we can repeat and apply it. There is no learning without studying. For this reason, the second part of the paper proposes ten steps for studying effectively (which permits understanding) and efficiently (using minimum effort). But how do we attain understanding? Often we reach understanding through personal experience; in most cases, however, we are helped by a professor, a teacher or a textbook that provides us with an explanation. The explanation process represents the topic of the third part of the paper, where the author considers the five most important structures of the explanation processthe common, classical, procedural, systemic and teleological structures. In this sense, Understanding, Studying and Explaining can be considered the three pillars on which are based learning and knowledge.

\section{Keywords}

Education, Understanding, Learning, Knowledge, Discipline of Studying, Explanation Process

\section{Introduction}

Throughout my decades-long teaching experience, I have always begun my courses (which are technical in nature) with a brief questionnaire in which students are asked to indicate the meaning behind their participation in 
the lessons and my role as teacher. In particular, I ask them if they attribute a different meaning to the terms "understanding" and "learning" and if, in their opinion, understanding is the cause or the effect of learning. I would get a variety of responses, some of which were even quite humorous. However, one thing definitely emerged: most of the students considered understanding and learning as synonymous, and a fair percentage of them held that learning necessarily preceded understanding. Most students felt that my task as a teacher was to explain to them the content of the course textbook and of my slides, which served to clearly present the main content of the course, thereby facilitating more rapid study. Everything became obvious when I took up the topic "What is the purpose of studying?" To answer this question I coined the phrase "between understanding and learning there is studying".

What does studying mean? The main answer was: "Reading and memorizing the book in order to answer the questions and pass the exam". It was precisely this simplistic way of considering the concept of studying that led me to propose a rulebook of advice for effective and efficient studying, which I still post on my course website. The most varied responses came from the question on the meaning of the term "explain" and the various forms of explanation, even if most students held that the main task of the teacher was to explain by "making clear and understandable the study material".

Benefitting from this experience, I have decided to summarize in this brief study the answers I gave my students regarding the questionnaire, at the same time clarifying the fundamental processes that constitute our understanding and develop our intelligence. I shall begin by analyzing the concepts of "understanding" and "learning" in the attempt to get across the message that in order to understand and learn we must remove the barriers to learning that unfortunately exist all too frequently for learners. I then indicate a ten-step approach to the discipline of studying, concluding with a presentation of the various forms of explanation that can be used to derive knowledge from other knowledge.

\section{First Pillar. Understanding and Learning. Models Are the Foundation of Knowledge}

Both as an individual and as part of an organization, man develops intelligent thinking that is manifested through knowledge and advantageous action, including the communicative processes. We all know that intelligent persons are more ready to solve problems, to be fair in their judgments and to behave in a rational and advantageous manner regarding their own existence as well as that of the groups and organizations to which they belong.

Intelligent persons are those who understand (and comprehend) quickly and effectively; who are not content to "look at the world with their eyes" (objects, facts, phenomena and processes) but who are able "to see the world with their minds" by constructing models to "understand" how the world is (description), how it functions (simulation), and how we can act as part of it (decision and planning), even without having the need, or possibility, of "looking at everything” (Mella, 2012: p. 3).

The Stupidity Test devised by Carlo Cipolla in his essay on The Basic Laws of Human Stupidity (Cipolla, 1988) also refers to the intelligent person as one who behaves in an advantageous manner regarding himself and others: "An intelligent person is one who voluntarily acts to gain advantages for himself, and for this reason produces advantages for others as well. To gain more advantages the intelligent person must also continually increase the advantages for others" (Mella, 2014b: p. 6).

Is there a way to become more intelligent? The answer is "Yes!". This is based on the hypothesis that intelligent persons have a high capacity to understand and learn effectively because they have developed the capacity to construct a system of coherent sense-making models (synonyms: representations, concepts, images, schema, maps, systems, etc.) and to quickly and continually modify these to advance their own knowledge.

There are three fundamental cognitive processes for gaining knowledge:

- Understanding: constructing coherent models that make sense of reality and the world around us in order to represent or develop concepts (synonyms: comprehend, mentally grasp, be clear about, penetrate with the mind, place in a framework, intellectualize, etc.); understanding implies explanation;

- Learning: knowing how to use the models developed in the understanding phase in order to further understand or modify reality (synonyms: acquiring, knowing, ascertaining, etc.); learning implies study;

- Explaining: deriving new models from other ones. 
The simplest models are the iconic and verbal ones formulated in a current language; the most sophisticated ones are those constructed using formal languages (from math, logic, statistics, systems theory). In order to control reality, simulation models which allow us to investigate the forecasted dynamics of reality are useful:

If the capacity to see and not simply look at [the world] depends on the ability to construct models to understand, explain and simulate the world, then the most useful and effective models to strengthen our intelligence are the systems ones based on the logic of Systems Thinking (Mella, 2012: p. 6).

My opinion is based on the premise that Systems Thinking represents the fundamental tool for constructing and communicating models that allow us to understand a dynamic, continually-evolving world.

\section{The Power of Systems Thinking}

Systems Thinking is a cognitive discipline presented by Peter Senge in his book The Fifth Discipline: The Art and Practice of the Learning Organization (Senge, 1990). Other terms can also be used to indicate this new way of thinking. Barry Richmond, one of the most renowned experts in this discipline (he was the founder, in 1984, of the High Performance System) stated:

Systems Thinking, a Systems Approach, Systems Dynamics, Systems Theory and just plain "Systems" are but a few of the many names commonly attached to a field of endeavor that most people have heard something about, many seem to feel a need for, and few really understand. [...] As I prefer the term "Systems Thinking," I'll use it throughout as the single descriptor for this field of endeavor (Richmond, 1991: p. 1).

Systems Thinking is a Paradigm and a Learning Method. The first conditions the second. The second supports the first. The two parts form a synergistic whole (Richmond, 1994: online).

According to Systems Thinking, in order to understand and explain reality we must represent it in terms of dynamic, repetitive and interconnected systems; objects observed from a static vision, non-repetitive systems, individual phenomenon, simple causes, simple effects, a lack of memory: these are the errors Systems Thinking tries to eliminate. Systems Thinking is based on the following simple general principles (Mella, 2012):

Holonic vision. Every observable object (galaxies, planets, organisms, cells, quarks) must be interpreted as an element that is composed of parts and, in turn, is part of a larger group (Koestler, 1967); similarly, Systems Thinking teaches us that every system is composed of sub-systems which are part of a super-system (Mella, 2009).

Systemic vision. Each event, phenomenon, datum, quantity, quality, number, etc., must always be observed, conceived and interpreted as an input or output of a process that is part of some dynamic system, the map of whose structure and processes must be constructed. We must avoid simplistic causal explanations, which explain phenomena in terms of causes, or simplistic functional explanations, which explain outputs as a function of inputs.

Structural vision. Every phenomenon is derived not from causes or inputs but from a process that depends on a structure, and thus on an organization, or on stable relations that act according to a program. To understand a phenomenon we must reconstruct the structure that it triggers, if it is an input phenomenon, or from which it is generated, if it is an output phenomenon.

Circular reasoning. In order to understand a phenomenon linked to a system, we must go beyond the linear logic of the cause-effect relationship and follow that of systemic interdependence and multiple loops: every output of a dynamic system derives from a multiplicity of inputs and directly and indirectly represents, to a greater or lesser degree, future inputs.

Circular reasoning allows us to make our explanation more efficient since:

- It obliges us to consider the circular relations among phenomena, the interconnections among processes and systemic structures, and not to limit ourselves to considering only the immediate interdependencies but to verify the existence of other interconnections;

- It requires that we specify the point of view of our observations; every phenomenon is an input or output of a system according to our point of observation;

- It forces us to consider our own actions as elements in a system of interdependent decisions; we must never forget that we are cognitive systems and that our behavior depends on the entire state of knowledge; a state that, however, is modified precisely as a result of our own actions, thereby initiating the process of learning 
from experience;

- It obliges us to reflect on the causes of our behavior, making us aware that the effects of today's actions can be a motivation for tomorrow's actions and that we are not only spectators but also actors with regard to the events that befall us.

\section{Knowledge and the Power of Models}

Models not only represent the result of our cognitive activity but guide our observation; they are thus indispensable instruments for both understanding and explanation. Knowledge (both individual and collective) is the system of coherent and sense-making models we have understood, learned and stored. The knowledge process (knowing) is the formation and continual modification of the system of models that constitute knowledge.

Knowledge is cumulative and dynamic and the knowledge in existence up until a given moment guides the formation of future knowledge. Argyris \& Schön (1974), (see also Argyris, 1993) consider two types of processes for producing knowledge from knowledge: single-loop learning, which increases the stock of knowledge within an existing framework of knowledge, and double-loop learning, which modifies and continually verifies the knowledge acquired, critically examining it and subsequently modifying and increasing it. If man wants to improve his knowledge he must not only adapt but also develop a pro-active cognitive behavior, re-examining and changing the models that make up his knowledge, thereby anticipating change in the world.

The learning process is the formation and continual improvement of the system of models that constitute knowledge. If learning is the accumulation and perfecting of models, understanding is always relative to our stock of knowledge, because it is facilitated by knowledge of other models, by the availability of effective conceptual tools (algorithms, heurisms, explanations, etc.), or by the possibility of using efficient operative tools (computers, maps, simulators, etc.).

We can distinguish between mental models and formal models. The former are the models intelligent people create in their "private" mental sphere to represent the content of the meaning they wish to transmit (if they are the sender) or interpret (if they are the recipient), which is used to evaluate "the world" and to make instinctive decisions.

The psychological core of understanding, I shall assume, consists of having a "working model" of the phenomenon in your mind. If you understand inflation, a mathematical proof, the way a computer works, DNA, divorce, then you have a mental representation that serves as a model of an entity in much the same way as, say, a clock functions as a model of the earth's rotation... Many of the models in people's minds are little more than high-grade simulations, but they are none the less useful provided that the picture is accurate (Johnson-Laird, 1983: pp. 2, 4).

Formal models are made up of systems of concrete signs, linguistic or symbolic, which formalize and transfer meaning and are used to communicate efficiently. Without models, recipes or processes it would not be possible to learn mathematics, biology, engineering, or even how to repair a mobile phone or an engine, make a cake, etc. Between a goal and behaviour is the devising of models, memorization and use. Understanding is the guide for the construction of such models. Studying is the process leading to the subjective mastering of such models.

Models not only represent the result of our cognitive activity but guide our observation; they are thus indispensable instruments for both understanding and explanation. Knowledge (both individual and collective) is the system of coherent and sense-making models we have understood, learned and stored. The knowledge process (knowing) is the formation and continual modification of the system of models that constitute knowledge.

Without entering into details it is useful to remember that according to our awareness of knowledge, we can distinguish between:

1) Explicit or declarative knowledge (conscious): This is composed of all the models we consciously apply in order to observe or act; these models can be communicated from one person to another and can be further classified into: a) memorized or codified knowledge: these are models we utilize in so far as they are memorized-in which case they include descriptions, concepts and habitually-applied routines (present knowledge)—or reconstructed from memory when necessary (latent knowledge); b) stored knowledge: this is formed by all the models stored in bases of knowledge which can be used as needed (the Internet and Google);

2) Tacit or non-declarative (non-conscious) knowledge (von Krogh et al., 2000): This is composed of all the "mental models" and all the programs and routines, operational and applied, that we have accumulated and which condition our actions, observations or experiences without our being aware of it or without our knowing 
how to communicate such knowledge.

I shall reconsider human knowledge by starting from the fact that we can know more than we can tell. This fact seems obvious enough; but it is not easy to say exactly what it means. Take an example. We know a person's face, and can recognize it among a thousand, indeed among a million. Yet we usually cannot tell how we recognize a face we know. So most of this knowledge cannot be put into words (Polanyi, 1967: p. 4).

Tacit knowledge can be divided into: a) Automatic knowledge, which derives from the presence of certain manual and other operational skills in using particular instruments; b) Implicit knowledge, which can be translated into the concept of knowing why; c) Combinatory knowledge, which derives from the ability to generate pattern matching processes; that is, parallel and simultaneous combinations of various types of knowledge (Leonard \& Sensiper, 1998).

\section{Second Pillar. A Ten-Step Approach to the Discipline of Studying}

It should be clear that understanding and learning represent different mental activities: between understanding and learning there is studying. Studying means applying, repeating and memorizing a model so that we can move from the understanding to the learning phase. Studying using a text is typically a one-way awareness: From the text a flow of models and concepts is transmitted to the student, without the latter being able to interact with the author. However, there is also study that is guided by a teacher who encourages dialogue and interaction, thereby producing a two-way awareness. The verification of what we know is always based on doing (application) or repeating (answering).

Not only is studying an art, a practice to apply, but it must become a true discipline to be constantly applied and improved over time. For this reason a ten-step approach to effective and efficient studying is proposed. These steps represent simple rules for gaining awareness of three fundamental aspects: 1) Why study? 2) How to study, and 3) What to study. As a detailed discussion of these aspects is beyond the scope of this paper, 10 relevant aspects will be summarized as follows.

\subsection{Why Study?}

1) Knowledge is life. Behaviour-which derives from causes, objectives and system constraints-is based not only on the knowledge of formal models we have learned but also on our experiences in constructing models created by our behaviour, as well as on the ideation process that produces new models and new "schemas" (Gell-Mann, 1994: p. 22) from the observation of reality.

To put it simply, people need a goal, a means, a resource and they need to pay attention to the resultswhich are the effects on our own experiences. These elements weave together in a closed circle that builds control (Mansell, 2011: online).

It is a great mistake to suppose, even tacitly, that the traditional schoolroom was not a place in which pupils had experiences. Yet this is tacitly assumed when progressive education as a plan of learning by experience is placed in sharp opposition to the old. The proper line of attack is that the experiences which were had, by pupils and teachers alike, were largely of a wrong kind. How many students, for example, were rendered callous to ideas, and bow many lost the impetus to learn... (Dewey, 2007: p. 26).

However, we must be aware of knowing, knowing how to know and trusting in knowing. Learning is the construction of models that guide behaviour and form knowledge.

2) Study is necessary. "Between understanding and learning there is studying". We must try to identify the objectives whose achievement requires studying. Studying is not an end in itself but a necessary feature of acquiring the knowledge needed for self-fulfillment. The teacher and the text make us understand, but we always learn by ourselves, through the will to do so.

The learning process must not be guided by causes; studying requires motivation and is necessary for the achievement of objectives: "I want to study because my goal is..." This is the most valid motivation for studying; I must study because:

- I need to graduate.

- It is necessary in order to find a job.

- It is what my family desires. 
- I must follow in my brother’s footsteps.

- I must set a good example for my brother who is still in high school.

- etc.

We learn if we want to learn; that is, if we want to understand and want to study; without motivation learning is difficult if not impossible (Schiefel, 1991).

Learning is a purposive activity-it is willful, deliberate and intentional, and it is manifest in a person's activity, behavior, outlook — in short, his or her way of being in the world [...]. This means that learning comes to bear in the context of an agenda, that is, it happens when someone strives to achieve, when somebody "reaches" for something. As learning is purposive, we cannot receive an education; we must take an education (MacKinnon, 2013: p. 16).

Above all, there is need for an interest in studying and for that interest to elicit the spontaneous, rather than conscious, selective allocation of attention toward a topic we wish to study (Hidi, 1990) interest is central in determining how people select certain types of studies in preference to others and persist in them.

The art of studying represents a discipline, in that it represents an exercise of will even more so that one of pure understanding and memorization. Living life to the full means learning and studying all through life.

3) We learn by ourselves. Generally we tend to attribute to others (a professor, a text, circumstances, time) the reasons for our failure to learn, but this often depends on our mental barriers to learning, in particular the lack of motivation, which frequently is expressed in the following ways:

- Studying serves no purpose;

- I don't understand; they don't explain it to me;

- The book isn't clear;

- The school has not provided me with the necessary means;

- The professor doesn't know how to explain things;

- What I have to study is not useful for me;

- I don't like the subject;

- There's too much to study;

- I have other things to do;

- I don't feel like it;

- etc.

Finding the barriers to learning and removing them is necessary if we want to learn new things or teach new things.

Lean and Colucci (2010) define and classify the mental barriers to learning as follows:

Definition of barriers to learning. A factor, condition, or situation that obstructs or impedes academic progress. Can be temporary (short-term, long-term) or permanent. Effect of barriers to learning range from mild (e.g., lower marks) to severe (e.g., dropping out).

Classification of barriers to learning. [...] Biological-psychological barriers to learning (constitutional/innate or psychological/emotional). Environmental-circumstantial barriers to learning (student's environment). Nature of interventions and resulting outcomes (Examples include bullying, absenteeism, family dysfunction) (ibidem: 2).

It is indispensable to find and remove these barriers that inhibit our minds from constructing and systemizing models. In many cases the task of recognizing and eliminating the barriers to learning falls to educational institutions.

\subsection{How to Study}

4) To study “well”. Studying “well” means not studying too much but doing so regularly, without frenetic bursts of activity (... I pulled an "all-nighter”...); that is, studying continually and methodically. An inefficient method gives us the certainty of not knowing. Too much study creates anxiety and doubt about knowing.

To study "well" we must have the right environment and be in the right state of mind, one which favors concentration and attention. Our mental states depend on our "attention", a "mental organ” which still has not been thoroughly studied and whose functioning produces mental fatigue (Ceccato, 1969). We must allow the attention 
organ to "rest” by interrupting our studying with some form of “distraction”. It is equally important not to overtax this organ by studying in environments which are unsuitable in general, noisy, poorly lit, and uncomfortable from a physical as well as mental point of view. It is also advisable not to distract our attention by studying while listening to music or with other sources of distraction and fatigue (studying well).

Each of us must find the right space and time for studying. Do not juxtapose the study of models, which are too different from one another but instead, attempt to create synergies in the study of similar and complementary subjects. Devising a study plan you are convinced can be followed and abiding by its time frame is more important than locking yourself in your room to avoid distractions.

5) Studying beforehand. If there is a text, it is useful to study before the professor explains it. Only in this way do we have the proof and confirmation of having understood the text's cognitive models. Only in this way can we ask for a specific clarification or explanation and engage in constructive dialogue.

6) Studying in terms of systems. As knowledge is a system of mental and formal models (concepts, ideas), studying must also be systemic, with each new concept linked to and ordered against others. The network of concepts must regularly be broadened and reordered; do not study sets of models as if they were a "telephone book”, but construct knowledge systems and networks. Only a system of correlated knowledge forms a cognitive model.

7) Study with others. Studying is normally one-way knowledge. Nevertheless, sooner or later we have to verify what we have learned. We can say we have learned something when we are able to reproduce the model that represents this knowledge, or when we know how to apply it. Sometimes we think we have learned something, but in reality we cannot be sure of this until we can demonstrate this knowledge through doing; that is, through behaviour (operational knowledge) or dialogue (speculative knowledge). For this reason we must study:

- Through practice, in order to learn by doing (practical learning);

- Together with others, in order to learn through dialogue (two-way learning).

\subsection{What to Study}

8) Studying subjects and not texts. A text is a container with cognitive content with a uni-directional transmission (Popper's third world).

Without taking the words "world" or "universe" too seriously, we may distinguish the following three worlds or universes: first, the world of physical objects or of physical states; secondly, the world of states of consciousness, or of mental states, or perhaps of behavioural dispositions to act; and thirdly, the world of objective contents of thought (Popper, 1972: p. 105).

We must study the content of the text-that is, the subject matter-not the text, the form in which the subject is expressed. To master the subject of a book, don't read the same book several times, but several books on the same topic.

9) Studying "more" than what we feel is sufficient. The broader the network of knowledge, the more certain is our knowledge and behavior. We must not merely study the bare minimum that is required; it is indispensable to go beyond the threshold of what is sufficient in order to complete our preparation (study more). To master a concept we must go outside the "logical networks" of this concept and use models which are correlated or at least connected to that concept. Forming more complex models is an assurance that we will understand and use the simpler ones. If you must know the equivalent of 10, study to know 20, because normally you will only be able to use $50 \%$ of what you know.

10) Studying "other subjects". To progress in the knowledge of a subject we must break free from the logical networks of this knowledge and use the concepts of "other types of knowledge”. Gödel's theorem could also be applied to knowledge, since a system of knowledge can never be at the same time complete and non-contradictory. In order to go beyond the limits of a specific system of knowledge we must move away from the system through other types of knowledge. Using the analogy of the area of a rectangle (area of a rectangle $=$ base $\times$ height), we can consider the "quantity of knowledge" as: cognitive broadening = variety $\times$ profundity. Often the variety of our models is more important than their profundity.

\section{Third Pillar. The Explanation Process and Its Operational Closure}

Knowledge progresses not only through studying or by making new observations but also through subsequent 
explanations. In plain words, explaining means guiding someone in the construction of a model through which understanding is reached. Explanations are a powerful means of understanding and the fundamental object of teaching, the process of explanation of a model held to be significant. The teaching can arise from requests for explanation by someone or it can be for the purpose of education. Education means teaching a system of models held to be useful for forming, guiding or modifying the conceptual structure of an individual, and thus his behaviour.

When man is faced with phenomena or events he cannot understand or manage a situation of ignorance exists that gives rise to the necessity to know (curiosity) which leads to a question that requires an explanation. The explanation is a process of guidance toward the construction of a model from which those phenomena or events could derive. Following Copi and Cohen (2011), in technical terms explaining a phenomenon F (explanandum) means constructing a model for it based on some other knowledge, thereby identifying a succession of statements; that is, a deductive argumentation (explanans) from which it is possible to derive $F$ as a valid conclusion. Every explanandum requires an appropriate explanans.

It is important to realize that the explanation is a backwards-recursive process: every explanans of an explanation becomes, in turn, an explanandum that can require a subsequent explanation, and so on up the line, just like the "game of why" that all children love to play. Any ignorance is explained by some piece of knowledge; but this in turn is based on other knowledge.

Let us indicate with $\mathrm{E}(\mathrm{n})$ the explanans and with $\mathrm{F}$ the explanandum; the recursive explanation then has the following structure:

F because $E(n)$,

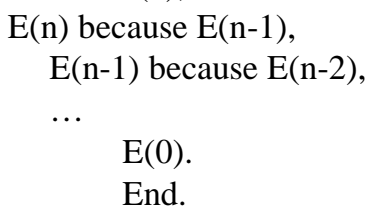

The explanation process is "closed" when we reach E(0); that is, an explanans with no further explanandum. For this reason $\mathrm{E}(0)$ can be defined as the operational closure of the explanation, which represents the point of ignorance, the limit to knowledge. $\mathrm{E}(0)$ can denote two possible forms of ignorance:

1) $\mathrm{E}(0)=$ "That which is not yet known". This represents reversible ignorance, which can take on the form of: a) temporary ignorance ("Research in progress...", "We are checking”, etc.); b) disinterest, that is, satisfaction with E(1) (“I'm not interested”, "Enough already!”); c) secretiveness, that is, the desire to hide knowledge ("I can't explain it to you").

2) $\mathrm{E}(0)=$ "That which we can never know". In this situation, operational closure represents irreversible ignorance, which can take various forms: a) permanent ignorance, which reveals itself to be incapable of ever being known (Heisenberg's indetermination principle, Gödel and Turing's theorems, and others that are similar); b) the mysterious, which is the unknowable (ineluctable principles, myths, God, metaphysics or agnosticism, acts of faith, etc.); c) the postulate, that is, a non-demonstrable, assumed origin from which to derive the explanation ("We hypothesize that...", "Given that...”; "We assume that...", etc.); d) chance, in all its manifestations (quantum randomness, genetic mutations, initial impulses of combinatory systems, etc.); e) necessity, or the self-sufficiency of E(0) ("It must be like this", "It can’t be otherwise", "The immobile engine”, etc.). In these cases operational closure is an explanatory dogma.

After having outlined the main features of the explanation process, five types of explanation processes will be examined; they are the most relevant and rely on different premises.

\subsection{Common Sense, Descriptive or Contingent Explanation}

The so-called common (simplistic, unsophisticated or descriptive) explanation is the one we daily apply to justify some phenomenon or to answer some question. In the common explanation the phenomenon or question to explain is derived from models that usually describe what we must explain without looking for the underlying scientific or systemic causes; "The light has come on because Aldo has flipped the switch"; "He got a fever because he was bit by an insect", "It's raining because the sky is full of clouds", "He got into an accident because he was drunk", “... because he was unlucky”, etc. The general structure of this kind of explanation is as follows:

EXPLANANS $\rightarrow \mathrm{P}=$ descriptive, contingent or simplistic, unsophisticated premises: functions, aims, intentions, causes, chance, etc. 
EXPLANANDUM $\rightarrow \mathrm{F}=$ phenomenon to explain

CONCLUSION $\rightarrow$ F occurs because the premises $\mathrm{P}$ have occurred

OPERATIONAL CLOSURE $\rightarrow$ This is the last of the premises that recursively explain F.

The common explanation at times relies on intentions ("The light has come on because Aldo had to go into the garage"), chance ("I met Aldo because he happened to be passing by"), experience ("It's raining because I went out without my umbrella"), regularity or common sense laws ("This is a rainy spring because the winter was dry"). This type of explanation is usually expressed descriptively and does not make use of sophisticated qualitative/quantitative models (Hempel, 1965). Included in this typology are "historical explanations" as well as "attribution theory", in order to take into account one's own and others' behavior, attributing this to the most likely "causes", such as justification (Heider, 1958). Another theory included in this typology is the 5-Ws-Who, What, When, Where and Why - which accounts for most of the explanatory needs in our daily lives. The same phenomenon can thus give rise to a number of common explanations that depend on the most convincing factors and that usually allow for one or at most two levels: "You made a mistake because you were distracted. What are you thinking of?”; "I’m thinking of what I'm going to do tonight".

The contingent explanations can easily become "tautological" when we attempt to explain a phenomenon by merely providing its definition: "There is inflation because all prices are increasing"; "Internationalization is an inevitable process because all socio-political barriers must be overcome”; etc.

\subsection{Classical Scientific Explanation}

The classical explanations are those that are used in any scientific context where the explanans is a model, which, in addition to the initial conditions of the phenomenon to explain, C, also includes the causal laws or functional relations, $\mathrm{L}$, as well as the scientific theories, or assumptions that can take into account the explanandum, according to the following schema:

EXPLANANS $\rightarrow \mathrm{T}=$ scientific theories and postulates, $\& \mathrm{~L}=$ scientific laws, \& $\mathrm{C}=$ initial conditions.

EXPLANANDUM $\rightarrow \mathrm{F}=$ phenomenon to explain.

CONCLUSION $\rightarrow \mathrm{F}$ is observed because, given the initial conditions $\mathrm{C}$, it follows from the laws $\mathrm{L}$, if we accept theory $\mathrm{T}$.

OPERATIONAL CLOSURE $\rightarrow$ The fundamental theories and postulates represent the operational closure of the explanation.

By varying the theoretical context and/or the laws adopted and/or the initial conditions, we also vary the explanation (Cupples, 1977). This form of explanation has become recognized as the scientific explanation par excellence.

Forty years ago a remarkable event occurred. Carl G. Hempel and Paul Oppenheim published an essay, "Studies in the Logic of Explanation," which was truly epoch-making. It set out, with unprecedented precision and clarity, a characterization of one kind of deductive argument that, according to their account, does constitute a legitimate type of scientific explanation. It came later to be known as the deductive-nomological model. This 1948 article provided the foundation for the old consensus on the nature of scientific explanation that reached its height in the 1960s (Salmon, 1990: p. 3).

Hempel claimed that "there are two types of explanation, what he called 'deductive-nomological' (DN) and 'inductive-statistical' (IS) respectively.” Both IS and DN arguments have the same structure. Their premises each contain statements of two types: 1) initial conditions C; and 2) law-like generalizations L. In each, the conclusion is the event $\mathrm{E}$ to be explained [...]. The only difference between the two is that the laws in a DN explanation are universal generalizations, whereas the laws in IS explanations have the form of statistical generalizations (IEP, online: 2-3).

\subsection{Procedural Explanations}

The procedural is a very common type of explanation, even though it has not received proper attention in the literature. It is used whenever a phenomenon (the square root of $\mathrm{Y}$ is?) does not derive from a particular model but rather appears to be the result of some elaboration or calculus, or the application of some algorithm, procedure or program (Gibbon, 1999). When we ask ourselves why the solution to extracting the square root of an expression does not correspond to the answer in our textbook, why our ticket wasn't drawn in the lottery, or why 
we ran into the bumper of the car in front of us, we must look for the answer in the procedure followed for the calculation or lottery drawing, or we must examine our parking attempt.

The procedural explanation can take on the following form:

EXPLANANDUM $\rightarrow \mathrm{F}=$ phenomenon to explain.

EXPLANANS $\rightarrow \mathrm{P}=$ procedure whose application produces $\mathrm{F} \& \mathrm{C}=$ conditions for applying the procedure.

CONCLUSION $\rightarrow$ F derives from $P$ applied under the conditions $C$.

OPERATIONAL CLOSURE $\rightarrow$ The procedure represents the operational closure of the explanation.

The procedural explanation always appears very convincing because not only is it the logical conclusion from the premise, it also allows us to reconstruct and emphasize the factual procedure (the logical or physical process) from which the conclusion emerges from (is produced or determined by) the premises. The systemic explanation represents the general form of the procedural explanation.

\subsection{Systemic Explanations}

The systemic explanation must be used when the explanandum cannot be reduced to a model that includes laws and theories (classical explanation) or results from the application of a procedure; instead it must be considered a phenomenon connected to the dynamics of some system process whose model we are trying to uncover. The systemic explanation must highlight the processes, $\mathrm{P}$, that have generated $\mathrm{F}$, which depends on the systemic structure $\mathrm{S}$ that supports those processes, the programs that guide the latter, and the environment $\mathrm{E}$ that conditions them (Mella, 1997: Section 2.16).

The model has the following structure:

EXPLANANDUM $\rightarrow \mathrm{F}=$ phenomenon to explain

EXPLANANS $\rightarrow \mathrm{S}=$ systemic structure that generates the explanandum $\mathrm{F}, \&$

$\Pi=$ programs that make the structure generate the processes, \&

$\mathrm{P}=$ processes generated by the structure $\mathrm{S}$ through the programs $\Pi, \&$

$\mathrm{E}=$ environment to which the system is coupled

CONCLUSION $\rightarrow \mathrm{F}$ derives from $\mathrm{P}$ produced by $\mathrm{S}$ in $\mathrm{E}$ by means of $\Pi$

OPERATIONAL CLOSURE $\rightarrow$ The system (environment-structure-programs-processes) represents the operational closure of the explanation.

The systemic explanation is thus more powerful, as it can take into account and justify any phenomenon whatsoever, from global warming to population dynamics, the deviation of the route of a space probe to the spread of epidemics (Mella, 2014a).

\subsection{Teleological Explanation}

The systemic explanations can be integrated by the teleological explanations, which try to take into account the behavior of a system with an objective (usually a biological one) by using the notion of "goal" or "objective" (Lennox, 1992).

The necessity of teleological explanations for biology has been questioned by the formalist tradition. We have seen that the ideal of explanation for the formalists is the deductive model. Many attempts have been made to incorporate teleological explanations into the deductive model. Indeed, such an incorporation is necessary if there is to be a formal reduction of biology to physics and chemistry. The basic line of argumentation is to subsume biological "goal-directed" systems under the wider category of "directively organized” systems which can apply to both living and inorganic systems (Plamondon, 1979: p. 153).

The teleological explanation has the following structure:

EXPLANANDUM $\rightarrow \mathrm{F}=$ dynamics of $\mathrm{S}$ to explain

EXPLANANS $\rightarrow \mathrm{S}=$ systemic structure that gives rise to explanandum $\mathrm{F}, \&$

$\mathrm{G}=$ Goal that $\mathrm{S}$ must achieve, \&

$\mathrm{C}=$ Control process carried out by $\mathrm{S}, \&$

$\mathrm{E}=$ environment to which the system is coupled

CONCLUSION $\rightarrow$ F derives from $\mathrm{S}$ in $\mathrm{E}$ because $\mathrm{C}$ directs $\mathrm{S}$ toward $\mathrm{G}$

OPERATIONAL CLOSURE $\rightarrow$ The Control System directing S to G represents the operational closure of the explanation. 
Precisely to the extent it is a science of guidance and communication, cybernetics today is mainly associated with the control of machines and mechanical systems. None other than Ludwig von Bertalanffy, considered to be the founder of General Systems Theory, recognized that:

[A] great variety of systems in technology and in living nature follow the feedback scheme, and it is wellknown that a new discipline, called Cybernetics, was introduced by Norbert Wiener to deal with this phenomena. The theory tries to show that mechanisms of a feedback nature are the bases of teleological or purposeful behaviour in man-made machines as well as living organisms and in social systems (von Bertalanffy, 1968: p. 44).

\section{The Best Explanation}

The best explanation is the one considered most likely; that is, the one that best satisfies the need for the individual or scientific community to take account of the explanandum. It is unthinkable that anyone would turn to physiological or psychological theories and laws, or to logistical processes, to explain "why there is no more mayonnaise in the fridge". While the classical explanation is particularly useful in the context of the experimental sciences, systemic explanation can also be used to explain individual, non-repeatable events involving unique facts deriving from a system's behavior. The former bases its validity on the initial conditions of the phenomenon in question and on a system of laws and theories that represent the final closure of the explanation process. Brought to mind are the words of Dixon and Emery, who warn against tautological scientific definitions:

When asked, for example, what happens to two blocks of copper initially at different temperatures left alone together in an insulated container, they will all reply that the blocks will come to the same temperature. Of course, if asked how they know, they usually say "Because it is a law of nature.” ... [T] is true... it is a law of nature because it happens (Dixon, 1965: p. 428).

The systemic explanation is based on the search for the most appropriate system model for deriving the explanandum $\mathrm{F}$ and has as its operational closure the boundaries of the system and the extension and organization of the network of processes that constitute its functioning. A good explanation must also enable accurate forecasts to be made. Forecasting the phenomenon $\mathrm{F}$ entails a reasoning process which, based on laws and particular conditions, allows one to deduce F before observing it (and independently of such observation).

It is immediately clear that the structure of the arguments from which the explanations or the forecasts derive is entirely analogous; the only difference is in the time dimension. If the explanandum is "given" (t1) as well as the explanans (t2), then we have an explanation; if, on the other hand, the premises refer to instant (t1) and the conclusion to (t2), the argumentation is in the nature of a forecast. While the quality of the explanation depends on the degree of confirmation the premises offer regarding the conclusion, the quality of the forecast depends conversely on the degree of confirmation the conclusion offers with regard to the premises. Thus, scientific and systemic explanations are preferred, since such argumentative structures are held to be the best in also providing accurate forecasts regarding the occurrence of $\mathrm{F}$.

In many circumstances a realistic approach must be followed. In their so-called "realistic" conception of knowledge, Stephen Hawking and Leonard Mlodinow recognize that all we can know about "reality" consists of networks of world pictures, or general models, expressed even through mathematical language:

In the history of science we have discovered a sequence of better and better theories or models, from Plato to the classical theory of Newton to modern quantum theories. It is natural to ask: Will this sequence eventually reach an end point, an ultimate theory of the universe, that will include all forces and predict every observation we can make, or will we continue forever finding better theories, but never one that cannot be improved upon? We do not yet have a definitive answer to this question... (Hawking \& Mlodinow, 2010: p. 8).

The explanation becomes unequivocal only when progress in the scientific field leads to one operational closure prevailing over the others. Multiple, equally valid, world pictures exist; therefore, science requires multiple models to encompass existing observations:

Like the overlapping maps in a Mercator projection, where the ranges of different versions overlap, they predict the same phenomena. But just as there is no flat map that is a good representation of the earth's entire surface, there is no single theory that is a good representation of observations in all situations...

(Hawking \& Mlodinow, 2010: p. 10). 
Finally, it should be noted that in order to understand and explain reality, Systems Thinking and System Dynamic approaches, applied jointly, allow us to produce the best systemic explanations through the construction of models and the simulation of their operation (Mella, 2012). System Dynamics is a discipline and technique that unquestionably goes back to Jay Forrester and his fundamental book Industrial Dynamics (Forrester, 1961). In recent works Forester defines Systems Dynamics as follows:

System dynamics combines the theory, methods, and philosophy needed to analyze the behavior of systems not only in management, but also in environmental change, politics, economic behavior, medicine, engineering, and other fields. System dynamics provides a common foundation that can be applied wherever we want to understand and influence how things change through time. The system dynamics process starts from a problem to be solved — a situation that needs to be better understood, or an undesirable behavior that is to be corrected or avoided. The first step is to tap the wealth of information that people possess in their heads. [...] System dynamics uses concepts drawn from the field of feedback control to organize available information into computer simulation models (Forrester, 1991: p. 5).

\section{Conclusion}

We connect to the world through our behavior and are thus part of the world. We are subject to and produce the fundamental variables of our own existence and that of others, and for this reason we must develop a systemic and pro-active learning for observing (understanding) judging (deciding), and identifying and solving problems. Thanks to models we can not only "understand and explaining the world" but above all "learn to live"- that is, to act, plan and foresee the future in order to improve our existence as well as that of our kin and descendants. The knowledge process (understanding, studying, learning, explaining) is the formation and continual modification of the system of models that constitute knowledge (Nonaka, 1994). According to Ichijo and Nonaka knowledge depends on individual perspectives and will; knowledge creation is an art, not a science.

The creation of knowledge is not simply a compilation of facts but a uniquely human process that cannot be reduced or easily replicated. It can involve feelings and belief systems that may not be conscious even for managers who create knowledge (Ichijo \& Nonaka, 2007: p. 85).

We must realize most times "what we are interested in understanding" cannot be observed; instead part of our "world" derives solely from models, which are often constructed without our being able to observe anything and, just as frequently, in contrast with what we observe: models represent reality, but reality derives from models. The explanation process reveals all its power to increase and refine knowledge.

In conclusion the relationship between the "three pillars of knowledge" can be fully understood by the model of Figure 1 which depicts knowledge as a circular process and illustrates the proactive experience process that

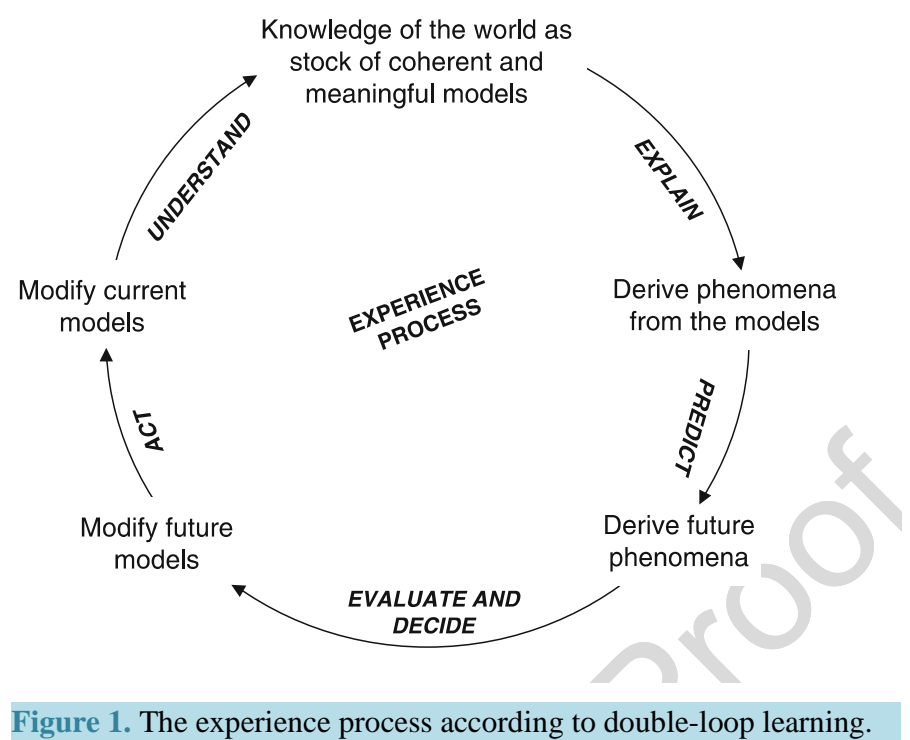


links the construction of models and the formation of knowledge with the explanation, evaluation, decisions and proactive actions regarding the world. The process is cyclical since such action on the world produces new stimuli that trigger a new cycle (Argyris, 1993; Argyris \& Schön, 1978, 1996; Sterman, 2000).

\section{References $^{1}$}

Argyris, C. (1993). Knowledge for Action. A Guide to Overcoming Barriers to Organizational Change. San Francisco: JosseyBass Publishers.

Argyris, C., \& Schön, D. (1974). Theory in Practice Increasing Professional Effectiveness. San Francisco: Jossey-Bass Publishers.

Ceccato, S. (1969). Course in Operational Linguistic [Italian: Corso di linguistica operativa]. Milano: Longanesi.

Cipolla, C. (1988). (eBook, 2011). The Basic Laws of Human Stupidity. Bologna: Il Mulino Ed. (eBook).

Copi, I. M., \& Cohen, C. (2011). Introduction to Logic (14th ed.). Edinburgh: Pearson.

Cupples, B. (1977). Three Types of Explanation. Philosophy of Science, 44, 387-408. http://dx.doi.org/10.1086/288756

Dewey, J. (2007). Experience and Education. New York: Macmillan. (Last edited by Simon and Schuster, 1st ed., 1938)

Dixon, J. R., \& Emery Jr., A. H. (1965). Semantics, Operationalism, and the Molecular-Statistical Model in Thermodynamics. American Scientist, 53, 428-436.

Forrester, J. W. (1961). Industrial Dynamics. Waltham, Mass: Pegasus Communications.

Forrester, J. W. (1991). System Dynamics and the Lessons of 35 Years. Cambridge, Mass.: MIT Press. ftp://nyesgreenvalleyfarm.com/documents/sdintro/D-4224-4.pdf

Gell-Mann, M. (1994). The Quark and the Jaguar. New York: W. H. Freeman.

Gibbon, D. (1998). Procedural Explanations.

http://coral.lili.uni-bielefeld.de/Classes/Summer98/PragEngDialogue/pragengdialogue/node18.html

Hawking, S. W., \& Mlodinow, L. (2010). The Grand Design. Bantam. Excerpt. http://bookre.org/reader?file=65691

Heider, F. (1958). The Psychology of Interpersonal Relations. New York: Wiley. http://dx.doi.org/10.1037/10628-000

Hempel, C. G. (1965). Aspects of Scientific Explanation and Other Essays. New York: The Free Press, \& London: CollierMacmillan.

Hidi, S. (1990). Interest and Its Contribution as a Mental Resource for Learning. Review of Educational Research, 60, 549571. http://dx.doi.org/10.3102/00346543060004549

IEP, Internet Encyclopedia of Philosophy (2014). Theories of Explanation. http://www.iep.utm.edu/explanat

Ichijo, K., \& Nonaka, I. (2007). Knowledge Creation and Management. New York: Oxford University Press.

Johnson-Laird, P. N. (1983). Mental Models: Towards a Cognitive Science of Language, Inference, and Consciousness. Cambridge, MA: Harvard University Press.

Keller, E. F., \& Lloyd, E. A., Eds. (1992). Keywords in Evolutionary Biology. Cambridge, MA: Harvard University Press.

Koestler, A. (1967). The Ghost in the Machine. London: Arkana.

Lean, D. S., \& Colucci, V. A. (2010). Barriers to Learning: The Case for Integrated Mental Health Services in Schools. Lanham, MA: R\&L Education ED.

Lennox, J. G. (1992). Teleology. In E. F. Keller, \& E. A. Lloyd (Eds.), 323-333.

Leonard, D., \& Sensiper, S. (1998). The Role of Tacit Knowledge in Group Innovation. California Management Review, 40, 112-132.

MacKinnon, A. (2013). The Heart of Learning. Creative Education, 4, 16-19. http://dx.doi.org/10.4236/ce.2013.412A2003

Mansell, W. (2011). Control and Purpose. A Scientific and Practical Statement in Response to the UK Riots 2011. http://www.pctweb.org/LondonRiots.pdf

Mella, P. (1997). From Systems to Systems Thinking: Understanding Systems and Thinking through Systems (Original: Dai sistemi al pensierosistemico: Per capireisistemi e pensare con isistemi). Milan: Franco Angeli.

Mella, P. (2009). The Holonic Revolution. Holons, Holarchies and Holonic Networks. The Ghost in the Production Machine. Pavia: University Press.

${ }^{1}$ As this paper deals with learning and knowledge considered from various points of view, the bibliography may appear to be boundless. Here I have only listed the works cited in this paper. All the sites mentioned have been visited in September, 2014. 
Mella, P. (2012). Systems Thinking. Intelligence in Action. New York and Berlin: Springer Verlag. http://dx.doi.org/10.1007/978-88-470-2565-3

Mella, P. (2014a). The Magic Ring. Systems Thinking Approach to Control Systems. New York and Berlin: Springer Verlag.

Mella, P. (2014b). The Social Wheel. Beyond Stupidity: “The Incapable Person is More Dangerous than the Stupid One”. A Tribute to Carlo Cipolla. Pensee Journal, 76, 2-11

Nonaka, I. (1994). A Dynamic Theory of Organizational Knowledge Creation. Organization Science, 5, 14-37. http://dx.doi.org/10.1287/orsc.5.1.14

Plamondon, A. L. (1979). Whitehead's Organic Philosophy of Science. New York: State University of New York Press.

Polanyi, M. (1967). The Tacit Dimension. Chicago, IL: University of Chicago Press.

Popper, K. R. (1972). Objective Knowledge. Oxford: Clarendon Press.

Richmond, B. (1991) Systems Thinking. Four Key Questions. Watkinsville, GA: High Performance Systems.

Richmond, B. (1994). System Dynamics/Systems Thinking: Let’s Just Get on with It. 1994 International Systems Dynamics Conference. http://webspace.webring.com/people/ah/himadri banerji/pdf/systhnk.pdf

Salmon, W. C. (1990). Four Decades of Scientific Explanation. Minneapolis MN: University of Minnesota Press.

Schiefel, U. (1991). Interest, Learning and Motivation. Educational Psychologist, 26, 299-323. http://dx.doi.org/10.1080/00461520.1991.9653136

Senge, P. (1990). The Fifth Discipline: The Art and Practice of the Learning Organization. New York: Doubleday/Currency. Sterman, J. D. (2000). Business Dynamics: Systems Thinking and Modeling for a Complex World. New York: McGraw-Hill. von Bertalanffy, L. (1968). General System Theory: Foundations, Development, Applications. New York: Braziller.

von Krogh, G., Ichijo, K., \& Nonaka, I. (2000). Enabling Knowledge Creation: How to Unlock the Mystery of Tacit Knowledge and Release the Power of Innovation. Oxford: Oxford University Press.

http://dx.doi.org/10.1093/acprof:oso/9780195126167.001.0001 
Scientific Research Publishing (SCIRP) is one of the largest Open Access journal publishers. It is currently publishing more than 200 open access, online, peer-reviewed journals covering a wide range of academic disciplines. SCIRP serves the worldwide academic communities and contributes to the progress and application of science with its publication.

Other selected journals from SCIRP are listed as below. Submit your manuscript to us via either submit@scirp.org or Online Submission Portal.
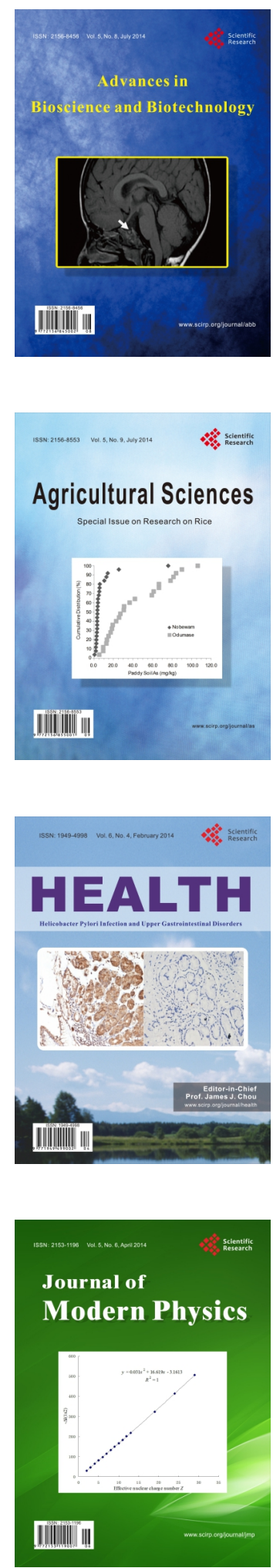
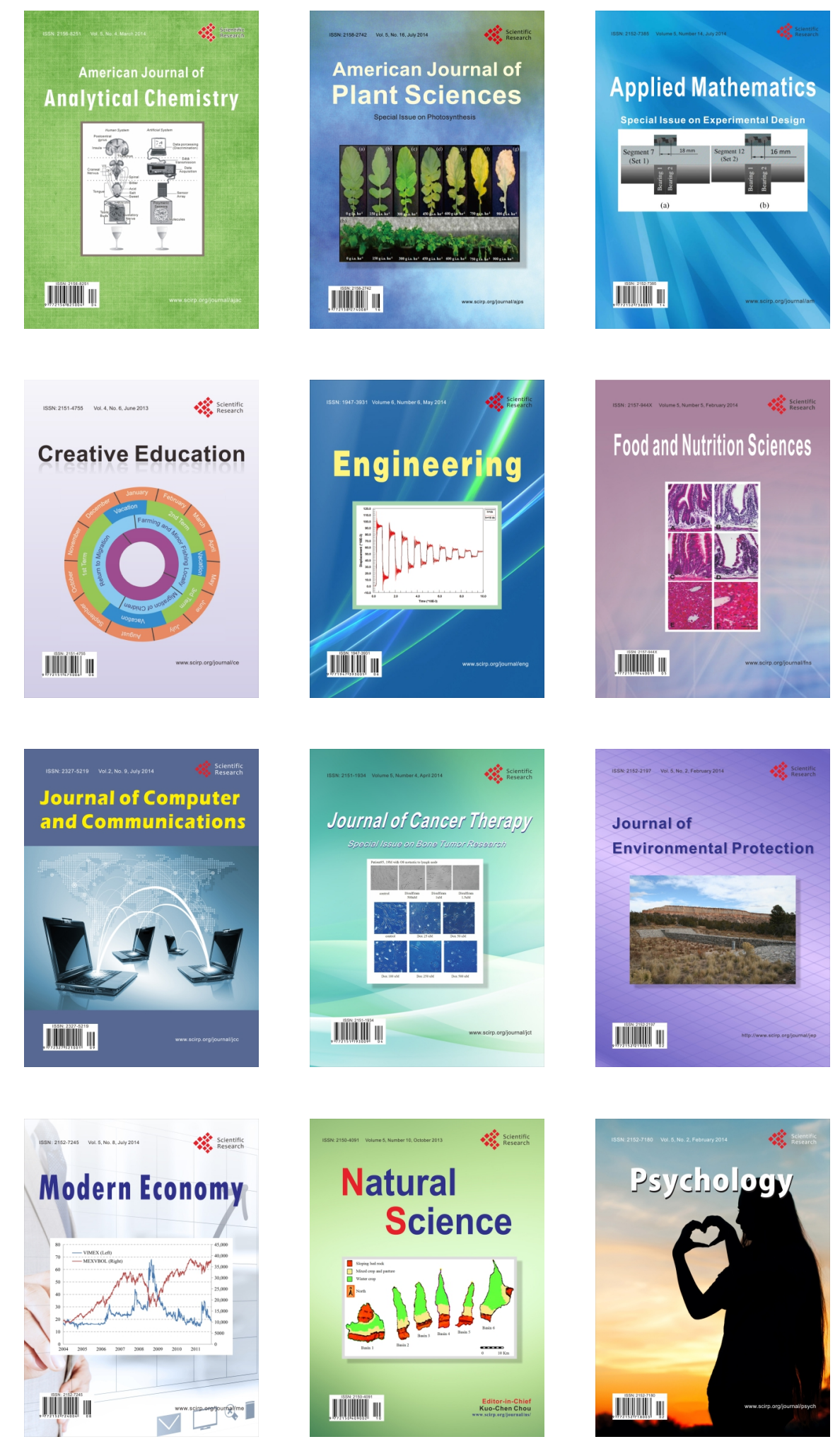